\title{
RESPONS PERTUMBUHAN GULMA TERHADAP KEPEKATAN CAIRAN FERMENTASI PULP KAKAO SEBAGAI BIOHERBISIDA PASCATUMBUH
}

\author{
Sujarman, Hermanus Suprapto \& Dad R.J. Sembodo \\ Jurusan Agroteknologi, Fakultas Pertanian Universitas Lampung \\ Jl.Prof. Soemantri Brodjonegoro, No.1, Bandar Lampung 35145 \\ E-mail:sujarman.20@gmail.com
}

\begin{abstract}
ABSTRAK
Cairan fermentasi pulp kakao mengandung asam organik dan polifenol yang mungkin dapat digunakan sebagai bioherbisida untuk mengendalikan gulma. Tujuan penelitian ini adalah untuk mengetahui respons empat jenis gulma terhadap aplikasi kepekatan cairan fermentasi pulp kakao sebagai bioherbisida pascatumbuh. Penelitian ini dilaksanakan dari bulan Maret sampai dengan Juli 2012 di Kecamatan Natar, Kabupaten Lampung Selatan. Percobaan menggunakan Rancangan Petak Berjalur (Strip Plot Design), ulangan 3 kali, dan perlakuan disusun secara faktorial (11 x 4) dengan ukuran petak $1 \mathrm{~m}$ x $2 \mathrm{~m}$. Faktor pertama adalah kepekatan cairan fermentasi pulp kakao (K) yaitu 0, 10, 20, 30, 40, 50, 60, 70, 80, 90, dan 100\% dan faktor kedua adalah jenis gulma (G) yaitu (a) Richardia brasilliensis, (b) Axonopus compressus, (c) Setaria plicata, dan (d) Cyperus kyllingia. Data dianalisis ragam dan dilanjutkan dengan uji BNT pada taraf $\alpha 0,05$. Hasil penelitian menunjukkan bahwa cairan fermentasi pulp kakao kepekatan 10-20\% tidak meracuni semua jenis gulma, tetapi pada kepekatan 30\% meracuni tiga jenis gulma dan tidak terhadap $C$. kyllingia. A. compressus menunjukkan respon keracunan tertinggi dibandingkan dengan gulma lain. Cairan fermentasi pulp kakao dengan kepekatan 100\% mampu menekan bobot kering gulma total. Bobot kering jenis gulma berbeda, C. kyllingia menujukkan bobot kering terendah dibandingkan dengan $R$. brasilliensis, A. compressus, dan S. plicata.
\end{abstract}

Kata kunci: bioherbisida, cairan fermentasi pulp kakao, gulma, pasca tumbuh

\section{PENDAHULUAN}

Pengelolaan kakao dengan cara fermentasi menghasilkan produk sampingan yang tidak banyak diperhatikan oleh masyarkat serta cenderung dianggap sebagai sampah dan pada akhirnya hasil sampingan ini dibuang begitu saja. Perlakuan fermentasi dalam pengolahan biji kakao menyebabkan biji menjadi berwarna coklat dan menghasilkan aroma kakao yang khas serta dapat mengurangi keasaman yang disebabkan lapisan pulp yang tebal. Produk sampingan yang diperoleh dari proses fermentasi kakao adalah limbah pulp. Pulp merupakan lapisan berwarna putih yang melapisi permukaan biji kakao (Nasution $d k k, 1985$ ). Cairan pulp adalah cairan yang diperoleh dari proses fermentasi biji kakao.

Pemanfaatan cairan fermentasi pulp kakao saat ini belum optimal dan hanya dibuang sebagai limbah organik ke lingkungan, mengalir melalui bak-bak fermentasi dan mencemari lingkungan. Cairan fermentasi pulp kakao sebenarnya juga dapat dimanfaatkan sebagai substrat produksi alkohol dan asam asetat sehingga perlu dicari teknologi pengolahan limbah kakao yang dapat menangani limbah dalam jumlah yang besar. Produksi lendir biji kakao mencapai 0,10 $0,191 \mathrm{~kg}^{-1}$ biji basah, pulp kakao mengandung glukosa dan sukrosa antara $12-15 \%$, asam-asam organik dan beberapa asam amino (Effendi, 2002).

Cairan fermentasi pulp kakao mengandung bahan yang memungkinkan dapat dimanfaatkan sebagai bioherbisida pascatumbuh untuk pengendalian gulma secara alami dan ramah lingkungan. Herbisida pascatumbuh merupakan herbisida yang diaplikasikan setelah gulma tumbuh (Sembodo, 2010). Pemanfaatan cairan fermentasi pulp kakao sebagai bioherbisida pra dan pascatumbuh relatif aman karena produk yang digunakan adalah produk alami yang dapat dengan mudah terurai, tidak seperti herbisida sintetis yang persisten. Cairan fermentasi pulp kakao mengadung asam-asam organik seperti asam malat, asam sitrat, asam asetat dan asam-asam amino serta polifenol (Atmana, 2000). Aplikasi tunggal pulpa kakao dosis 31 / ha menyebabkan daun klorosis pada gulma golongan berdaun lebar (Wahida, 2005 dalam Deptan, 2010). Klorosis ditandai dengan berubahnya warna daun menjadi layu dan seperti terbakar. Pemanfaatan cairan fermentasi pulp kakao sebagai bioherbisida perlu mengetahui kosentrasi yang tepat sehingga tingkat 
pengendalian gulma menjadi efektif. Herbisida cair dari pemanfaatan pulp kakao dihasilkan dengan cara mencampurkan pulp dengan air. Umumnya, perbandingan yang digunakan antara pulp dan air antara 1:10 sampai dengan 1:20 sehingga dihasilkan larutan pulp yang tidak terlalu pekat (Widyotomo, 2008).

Proses pemanfaatan cairan fermentasi pulp kakao belum banyak diketahui oleh masyarakat secara umum, sehingga sering terjadi permasalahan limbah pada saat proses pengolahan awal kakao. Untuk mengatasi permasalahan ini, maka dilakukan penelitian dengan harapan dapat mengurangi limbah cairan pulp kakao dan mengubahnya menjadi produk yang lebih bermanfaat.

Penelitian ini bertujuan untuk mengetahui respon empat jenis gulma terhadap tingkat kepekatan cairan fermentasi pulp kakao sebagai bioherbisida pascatumbuh.

\section{BAHAN DAN METODE}

Penelitian dilaksanakan dari bulan Maret sampai dengan Juli 2012 di Kecamatan Natar, Kabupaten Lampung Selatan. Cairan fermentasi pulp kakao diperoleh dari perkebunan kakao PT Peluit Mandiri Lestari (PML) di Desa Bernung Gedung Tataan, Kabupaten Pesawaran, Propinsi Lampung. Bahanbahan yang digunakan dalam penelitian ini adalah cairan fermentasi pulp kakao, air, gulma daun lebar (Richardia brasilliensis), rumput (Axonopus compressus, Setaria plicata) dan teki (Cyperus kyllingia), sedangakan alat yang digunakan adalah knapsack sprayer, nozzle biru, meteran, cangkul, tali rafia, cutter, ember, gelas ukur, pipet tetes, timbangan, oven, alat tulis, penggaris, dan kantong plastik.

Percobaan diterapkan dalam Rancangan Petak Berjalur (Strip Plot Design) masing-masing perlakuan diulang sebanyak 3 kali dengan ukuran petak $1 \mathrm{~m} \times 2 \mathrm{~m}$. Perlakuan disusun secara faktorial (11 x 4). Faktor pertama adalah kepekatan cairan fermentasi pulp kakao (K) yang terdiri 11 taraf yaitu kepekatan $0,10,20,30$, 40, 50, 60, 70, 80, 90 dan 100\%. Faktor kedua adalah jenis gulma (G) yang terdiri dari 4 taraf yaitu $R$. brasilliensis (a), A. compressus (b), S. plicata (c) dan C. kyllingia (d). Homogenitas ragam antar perlakuan diuji dengan uji Bartlett dan additifitas data diuji dengan uji Tukey. Bila asumsi terpenuhi maka data dianalisis ragam dan pemisahan nilai tengah dilakukan dengan uji BNT pada taraf nyata $5 \%$.

Pengolahan tanah dilakukan dengan cara dicangkul, kemudian petak perlakuan dibuat sebanyak 33 peta, dengan ukuran $1 \mathrm{~m} \times 2 \mathrm{~m}$. Gulma ditanam pada setiap petak perlakuan berisi 4 jenis gulma dan setiap jenis gulma sebanyak 12 anakan. Cairan pulp kakao difermentasikan selama 4 hari sebelum aplikasi. Aplikasi menggunakan knapsack sprayer dengan nozzle biru pada 1,5 bulan setelah tanam. Peubah yang diamati adalah, persentase keracunan gulma pada 1 hari setelah aplikasi (HSA), 2 HSA, 1 minggu setelah aplikasi (MSA) dan 2 MSA serta bobot kering gulma pada 2 MSA.

\section{HASIL DAN PEMBAHASAN}

Hasil penelitian menunjukkan terjadi interaksi antara kepekatan cairan fermentasi pulp kakao dengan jenis gulma. Hasil pengamatan pada 1 HSA menunjukkan bahwa perlakuan kepekatan 0-20\% tidak meracuni gulma (Tabel 1). Gejala keracunan gulma terlihat pada perlakuan kepekatan 30\% kecuali gulma C. kyllingia. Selanjutnya kepekatan 60-90\% tidak menunjukkan perberbedaan terhadap persentase keracunan gulma A. compressus dengan S. plicata, tetapi berbeda dengan $R$. brasiliensis dan $C$. kyllingia.

Respon jenis gulma berbeda terhadap kepekatan cairan fermentasi pulp kakao, A. compressus menunjukkan respon keracunan yang tertinggi jika dibandingkan dengan $R$. brasiliensis, $S$. plicata. dan C. kyllingia pada kepekatan $100 \%$. Persentase keracunan yang sama ditunjukkan oleh Richardia brasiliensis dengan $C$. kyllingi pada kepekatan cairan fermentasi pulp kakao $0-80 \%$, tetapi berbeda dengan A. compressus dan S. plicata.

Respon beberapa jenis tumbuhan yang berbeda pada satu jenis herbisida dengan dosis yang sama akan berbeda pula. Hal ini karena letak kegiatan herbisida itu pada masing-masing tumbuhan juga berbeda atau pun lama beradanya herbisida itu dalam tumbuhan yang berbeda (persistensi). Kemantapan beradanya herbisida dan letak kegiatannya dalam tubuh tumbuhan mempunyai hubungan yang erat dengan keselektifannya, penetrasi dan translokasinya untuk mencapai sasaran (Moenandir,1988).

Persentase keracunan gulma mulai terlihat pada kepekatan cairan fermentasi pulp kakao $30 \%$ pada ke empat jenis gulma $R$. brasiliensis, A. compressus, $S$. plicata dan C. kyllingia. Peningkatan kepekatan cairan fermentasi pulp kakao meningkatkan persentase keracunan jenis gulma sampai pada kepekatan 100\% (Gambar 1). Moenandir (1988) menyatakan bahwa semakin tinggi konsentrasi herbisida yang diterima oleh gulma akan meningkatkan penekanan herbisida terhadap pertumbuhan gulma tersebut.

Persentase keracunan gulma $R$. brasiliensis, A. compressus, $S$. plicata dan $C$. kyllingia meningkat sampai 2 HSA, sedangkan pada 1 MSA dan 2 MSA 
Tabel 1. Pengaruh kepekatan cairan fermentasi pulp kako dan jenis gulma terhadap persentase keracunan gulma (\%) pada 1 HSA

\begin{tabular}{|c|c|c|c|c|}
\hline \multirow{2}{*}{$\begin{array}{l}\text { Kepekatan cairan } \\
\text { fermentasi pulp } \\
\text { kakao }(\%)\end{array}$} & \multicolumn{4}{|c|}{ Jenis gulma (data asli) } \\
\hline & Richardia brasiliensis & Axonopus compressus & Setaria plicata & Cyperus kyllingia \\
\hline 0 & 0,00 & 0,00 & 0,00 & 0,00 \\
\hline 10 & 0,00 & 0,00 & 0,00 & 0,00 \\
\hline 20 & 0,00 & 0,00 & 0,00 & 0,00 \\
\hline 30 & 3,33 & 4,67 & 5,00 & 1,00 \\
\hline 40 & 9,33 & 19,67 & 9,67 & 8,33 \\
\hline 50 & 6,00 & 35,33 & 15,33 & 7,67 \\
\hline 60 & 13,00 & 44,33 & 20,00 & 10,67 \\
\hline 70 & 13,33 & 66,33 & 27,67 & 11,67 \\
\hline 80 & 18,00 & 62,00 & 28,00 & 10,00 \\
\hline 90 & 23,00 & 64,33 & 29,33 & 13,33 \\
\hline 100 & 41,00 & 95,67 & 49,00 & 19,00 \\
\hline \multirow{2}{*}{$\begin{array}{l}\text { Kepekatan cairan } \\
\text { fermentasi pulp } \\
\text { kakao }(\%)\end{array}$} & \multicolumn{4}{|c|}{ Jenis gulma (data transformasi $\sqrt{ } \sqrt{ }(x+0,5))$} \\
\hline & Richardia brasiliensis & Axonopus compressus & Setaria plicata & Cyperus kyllingia \\
\hline 0 & $0,92 \mathrm{a}$ & $0,92 \mathrm{a}$ & $0,92 \mathrm{a}$ & $0,92 \mathrm{a}$ \\
\hline & $\mathrm{a}$ & $\mathrm{a}$ & $\mathrm{a}$ & $\mathrm{a}$ \\
\hline 10 & $0,92 \mathrm{a}$ & $0,92 \mathrm{a}$ & $0,92 \mathrm{a}$ & $0,92 \mathrm{a}$ \\
\hline & $\mathrm{a}$ & $\mathrm{a}$ & $\mathrm{a}$ & $\mathrm{a}$ \\
\hline 20 & $0,92 \mathrm{a}$ & $0,92 \mathrm{a}$ & $0,92 \mathrm{a}$ & $0,92 \mathrm{a}$ \\
\hline & a & a & a & $\mathrm{a}$ \\
\hline 30 & $1,13 \mathrm{~b}$ & $1,22 b$ & $1,24 \mathrm{~b}$ & $1,00 \mathrm{a}$ \\
\hline & $\mathrm{ab}$ & $\mathrm{b}$ & $\mathrm{b}$ & $\mathrm{a}$ \\
\hline 40 & $\begin{array}{c}1,27 \mathrm{bcd} \\
\mathrm{a}\end{array}$ & $\begin{array}{c}1,39 b c \\
b\end{array}$ & $\begin{array}{c}1,27 \mathrm{~b} \\
\mathrm{a}\end{array}$ & $\begin{array}{c}1,29 \mathrm{~b} \\
\mathrm{ab}\end{array}$ \\
\hline 50 & $\begin{array}{c}1,24 \mathrm{bc} \\
\mathrm{a}\end{array}$ & $\begin{array}{l}1,55 \mathrm{~cd} \\
\mathrm{c}\end{array}$ & $\begin{array}{c}1,40 \mathrm{bc} \\
\mathrm{bc}\end{array}$ & $\begin{array}{c}1,28 \mathrm{~b} \\
\mathrm{ab}\end{array}$ \\
\hline 60 & $\begin{array}{c}1,38 \text { cde } \\
\mathrm{ab}\end{array}$ & $\begin{array}{c}1,60 \mathrm{de} \\
\mathrm{c}\end{array}$ & $\begin{array}{c}1,46 \mathrm{~cd} \\
\mathrm{abc}\end{array}$ & $\begin{array}{c}1,35 \mathrm{~b} \\
\mathrm{a}\end{array}$ \\
\hline 70 & $\begin{array}{c}1,39 \mathrm{cde} \\
\mathrm{ab}\end{array}$ & $\begin{array}{l}1,68 \mathrm{de} \\
\mathrm{c}\end{array}$ & $\begin{array}{c}1,51 \mathrm{~cd} \\
\mathrm{ab}\end{array}$ & $\begin{array}{c}1,37 \mathrm{~b} \\
\mathrm{a}\end{array}$ \\
\hline 80 & $\begin{array}{c}1,43 \text { def } \\
a b\end{array}$ & $\begin{array}{c}1,67 \mathrm{de} \\
\mathrm{c}\end{array}$ & $\begin{array}{c}1,52 \mathrm{~cd} \\
\mathrm{bc}\end{array}$ & $\begin{array}{c}1,34 \mathrm{~b} \\
\mathrm{a}\end{array}$ \\
\hline 90 & $\begin{array}{c}1,48 \text { ef } \\
b\end{array}$ & $\begin{array}{c}1,66 \mathrm{de} \\
\mathrm{c}\end{array}$ & $\begin{array}{c}1,52 \mathrm{~cd} \\
\mathrm{abc}\end{array}$ & $\begin{array}{c}1,39 \mathrm{~b} \\
\mathrm{a}\end{array}$ \\
\hline 100 & $\begin{array}{c}1,57 \mathrm{f} \\
\mathrm{ab}\end{array}$ & $\begin{array}{c}1,77 \mathrm{f} \\
\mathrm{c}\end{array}$ & $\begin{array}{c}1,61 \mathrm{~d} \\
\mathrm{~b}\end{array}$ & $\begin{array}{c}1,45 \mathrm{~b} \\
\mathrm{a}\end{array}$ \\
\hline
\end{tabular}

BNT jenis gulma $(0,17)$ dan kepekatan cairan fermentasi pulp kakao $(0,15)$

Keterangan: Huruf yang sama dibelakang angka dalam satu kolom atau huruf yang sama dibawah angka dalam satu baris menunjukkan tidak berbeda nyata berdasarkan uji BNT pada $\alpha_{0,05}$.

keracunan gulma terlihat menurun. Hal ini diduga mekanisme kerja bioherbisida cairan fermentasi pulp kakao bersifat kontak, yang hanya menyebabkan klorosis, gulma tidak mati dan pulih kembali (Gambar 2).
Herbisida kontak bereaksi pada bagian gulma yang terkena atau kontak langsung dengan herbisida dan tidak ditranslokasikan atau dialirkan dalam tubuh gulma. Semakin banyak organ gulma yang terkena herbisida akan semakin baik daya kerja herbisida tersebut 


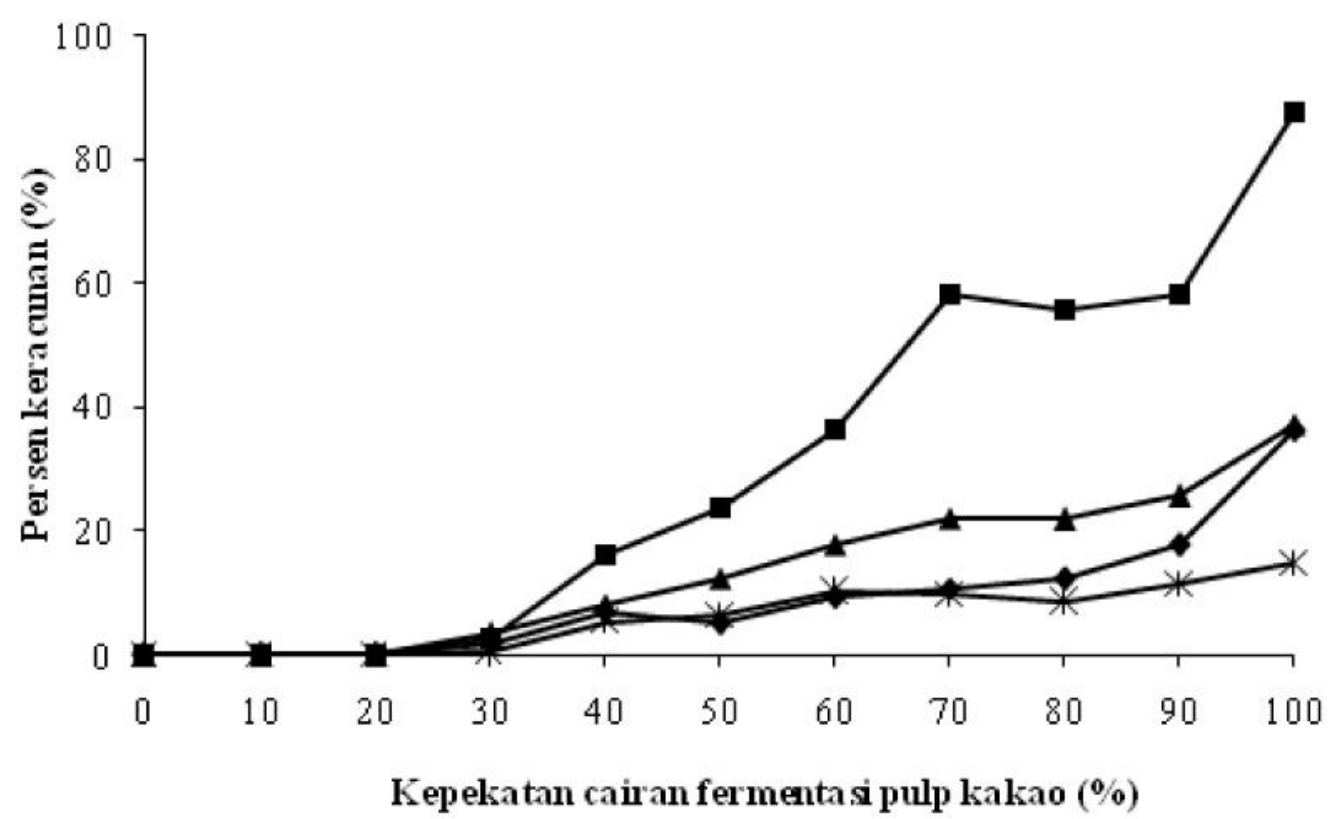

Gambar 1. Hubungan tingkat kepekatan cairan fermentasi pulp kakao dengan persentase keracunan gulma. $\boldsymbol{\bullet}=$ R. bransiliensis, $\boldsymbol{\square}=$ A. compresus, $\boldsymbol{\Lambda}=$ S. plicata, dan $*=$. kyllingia .

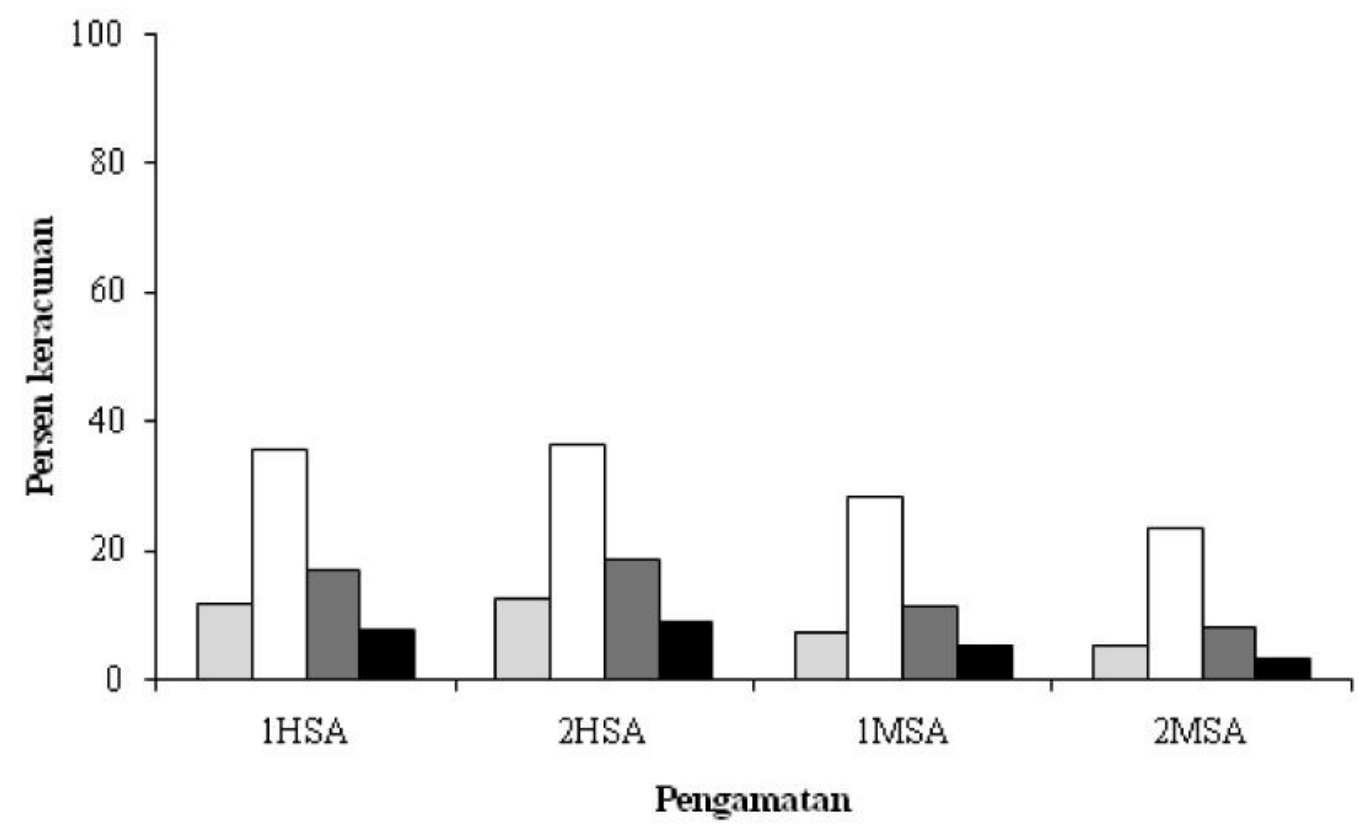

Gambar 2 . Persentase keracunan gulma pada pengamatan 1HSA, 2 HSA, 1 MSA, dan 2 MSA. HSA (hari setelah aplikasi dan MSA (minggu setelah aplikasi). $\square=R$. bransiliensis, $\square=A$. compresus, $\square=$ S. plicata, dan $\mathbf{\square}=$ C. kyllingia .

(Sembodo, 2010). Bagian gulma yang terkena aplikasi cairan fermentasi pulp kakao mengalami keracunan, tetapi tidak terjadi pada bagian yang tidak terkena, hal ini menyebabkan persentase keracunan semakin menurun karena bagian gulma yang tidak teracuni mengalami pemulihan.

Cairan fermentasi pulp kakao mengadung asamasam organik seperti asam malat, asam sitrat, asam asetat dan asam-asam amino serta polifenol (Atmana, 2000). Salisbury dan Ross (1995) menyatakan bahwa senyawa polifenol dapat bersifat racun bagi tanaman sehingga mengganggu pertumbuhan tanaman. Selanjutnya menurut Devi $d k k$, (1997) menyatakan bahwa senyawa polifenol menghambat pertumbuhan tanaman melalui beberapa cara, antara lain dengan menghambat pembelahan dan pemanjangan sel, 
menghambat kerja hormon, mengubah pola kerja enzim, menghambat proses respirasi, menurunkan kemampuan fotosintesis, mengurangi pembukaan stomata, menghambat penyerapan air dan hara serta menurunkan permeabilitas membran. Polifenol merupakan senyawa kimia yang banyak dimanfaatkan sebagai insektisida, herbisida dan fungisida. Sebagai herbisida, fenol sangat tinggi toksisitasnya, bersifat non selektif dan bekerja secara efektif merupakan herbisida organik dan sebagian besar bersifat kontak (Oudejans, 1991).

Hasil penelitian menunjukan bahwa kepekatan cairan fermentasi pulp kakao 100\% mampu menekanan bobot kering gulma total pada 2 MSA. Selanjutnya kepekatan cairan fermentasi pulp kakao 0-90\% mempunyai daya tekan terhadap bobot kering gulma total yang sama (Tabel 2). Bobot kering antarjenis gulma berbeda untuk setiap jenis gulma, bobot kering gulma $R$. bransiliensis berbeda dengan A. compresus, $S$. plicata, dan $C$. kyllingia pada pengamtan 2 MSA. $C$. kyllingia menujukkan bobot kering terendah dibanding dengan $R$. brasilliensis, A. compressus, dan S. plicata.

\section{KESIMPULAN}

Kepekatan cairan fermentasi pulp kakao 10-20\% tidak meracuni semua jenis gulma, tetapi pada kepekatan
$30 \%$ meracuni tiga jenis gulma dan tidak terhadap $C$. kyllingia. A. compressus menunjukkan respon keracunan tertinggi dibandingkan dengan gulma lain. Cairan fermentasi pulp kakao dengan kepekatan $100 \%$ mampu menekan bobot kering gulma total, bobot kering gulma $C$. kyllingia menujukkan bobot terendah dibandingkan dengan $R$. brasilliensis, A. compressus, dan S. plicata.

\section{DAFTAR PUSTAKA}

Atmana, S.A., 2000. Proses Enzimatis pada Fermentasi untuk Perbaikan Mutu Kakao. BPP Teknologi. http: www.iptek/terapan/cocoa.co.id.html. [17 November 2011].

Deptan. 2010. Pemanfaatan Pulpa Kakao. http:// epetani.deptan.go.id/blog/pemanfaatan-pulpakakao-1605 html. [17 November 2011].

Devi, S.R., Pellisier and Prasad. 1997. Allelochemical. In: M.N.V.Prasad (Eds).1997. Plant Ecophysiology. John Willey and Sons, Inc. Toronto, Canada. 253-303.

Tabel 2. Pengaruh kepekatan cairan fermentasi pulp kakao terhadap bobot kering gulma total pada 2 MSA

\begin{tabular}{cc}
\hline Kepekatan pulp kakao $(\%)$ & Bobot kering gu lma total $\left(\mathrm{g} / 0,25 \mathrm{~m}^{2}\right)$ \\
\hline 0 & $27,17 \mathrm{a}$ \\
10 & $23,58 \mathrm{ab}$ \\
20 & $22,83 \mathrm{ab}$ \\
30 & $18,02 \mathrm{ab}$ \\
40 & $20,67 \mathrm{ab}$ \\
50 & $23,00 \mathrm{ab}$ \\
60 & $24,08 \mathrm{a}$ \\
70 & $18,67 \mathrm{ab}$ \\
80 & $19,50 \mathrm{ab}$ \\
90 & $21,75 \mathrm{ab}$ \\
& $14,42 \mathrm{~b}$ \\
\hline BNT & 8,81 \\
\hline Jenis gulma & \\
\hline Richardia brasiliensis & $34,48 \mathrm{a}$ \\
Axonopus compressus & $16,24 \mathrm{c}$ \\
Setaria plicata & $23,49 \mathrm{~b}$ \\
Cyperus kyllingia & $10,85 \mathrm{~d}$ \\
\hline BNT & 3,42 \\
\hline
\end{tabular}

Keterangan: Huruf yang sama dibelakang angka menunjukkan tidak berbeda nyata berdasarkan uji BNT pada $\alpha_{0,05}$. 
Effendi M.S. 2002. Kinetika fermentasi asam asetat (vinegar) oleh bakteri Acetobacter aceti B127 dari etanol hasil fermentasi limbah cair pulpa kakao. Teknol Ind Pert. 13:125-135.

Moenandir, J. 1988. Fisiologi Herbisida (Ilmu GulmaBuku II). Rajawali Press. Jakarta. 143 hlm.

Nasution, M.Z., W. Tjiptadi, B.S. Laksmi. 1985. Pengolahan Cokelat. Bogor. Agroindustri Press. $161 \mathrm{hlm}$.

Oudejans, JH. 1991. Agro Pesticides: Properties and Function in Integrated Crop Protection. United Nations Bangkok. $329 \mathrm{hlm}$.
Salisbury, F.B. dan C.W. Ross. 1995. Fisiologi Tumbuhan. Terjemahan Lukman dan Sunaryono. ITB, Bandung. 338 hlm.

Sembodo. D.R.J. 2010. Gulma dan Pengelolaannya. Graha Ilmu. Yogyakarta. $166 \mathrm{hlm}$.

Widyotomo, S. 2008. Teknologi fermentasi dan diversifikasi pulp kakao menjadi produk yang bermutu dan bernilai tambah. Review Penelitian Kopi dan Kakao. Pusat Penelitian Kopi dan Kakao Indonesia. Jember. 24(1): 65-82. 